\title{
EFFECT OF FIRING TEMPERATURE AND GLASS CONTENT ON THE ELECTRICAL PROPERTIES OF THICK FILM CAPACITORS
}

\author{
S. LEPPÄVUORI and A. UUSIMÄKI \\ Department of Electrical Engineering, University of Oulu, Finland
}

(Received April 15, 1981; in final form October 25, 1981)

\begin{abstract}
A study was carried out to investigate the effects of the firing temperature of thick film capacitors on the capacitance density, loss factor and breakdown voltage. These effects were studied by varying the firing temperature and glass content of the dielectric paste and by using different types of electrode paste. The active part of the prepared paste was barium titanate and glass binder lead borosilicate glass.
\end{abstract}

\section{INTRODUCTION}

Many attempts to incorporate thick film capacitors into thick film hybrid circuits have been made in order to reduce the size, number of interconnections and cost of the circuits but the use of printed capacitors is still limited to thick film circuits. ${ }^{1}$ It appears that more knowledge concerning the materials and processing of thick film capacitors is needed.

This study clarifies the effects of firing temperatures on the electrical properties of a capacitor based on a dielectric of barium titanate, $\left(\mathrm{BaTiO}_{3}\right)$-glass formulation. The composition of the paste was selected so as to be able to separate the different effects from each other. Pure barium titanate was used as the ferroelectric material and a lead borosilicate glass as the glass frit. Commercial capacitor pastes are also based on barium titanate with the addition of depressors to flatten the strong temperature dependence of the permittivity of barium titanate. ${ }^{2}$

The electrode materials have a great influence on the properties of thick film capacitors. To study these effects different types of electrode materials were used.

The characteristics of barium titanate thick film capacitors were also measured to give general information concerning the dielectric properties of the capacitors.

\section{PREPARATION OF PASTES AND SAMPLES}

\subsection{Preparation of the Paste}

The active part of the paste was commercial grade barium titanate. Since the particle size of barium titanate in thick films is smaller than $50 \mu \mathrm{m}$, the permitti- vity of barium titanate depends strongly on particle size in and near room temperature, the value reaching a maximum value when the grain size is about $1 \mu \mathrm{m} .^{3}$ Because of this, a distribution of the particle size of the barium titanate near $1 \mu \mathrm{m}$ was used in this work.

The glass component of the dielectric paste was a lead borosilicate glass, $70 \mathrm{PbO}-18 \mathrm{~B}_{2} \mathrm{O}_{3}-12 \mathrm{SiO}_{2}$, which is stable and exhibits only a small tendency to react with barium titanate during firing. The softening point of this glass is approximately $520^{\circ} \mathrm{C}$ and the temperature expansion coefficient, approximately $7 \times 10^{-6} /{ }^{\circ} \mathrm{C}$, a value between that of barium titanate and aluminium oxide. The glass frit contents of the powder of the dielectric pastes were $3,5,7,14,21$ and $28 \mathrm{wt}-\%$.

The organic vehicle used was $10 \mathrm{wt}-\%$ ethyl cellulose dissolved in butyl carbitol acetate. Differential temperature analysis and temperature gravimetric analysis showed that during the firing process, the larger part of the organic vehicle burnt off at around $285^{\circ} \mathrm{C}$ and nearly all the remainder left the printed layer, before the softening point of the glass at around $500^{\circ} \mathrm{C}$

Figure 1 shows the different steps of the preparation of the paste. Commercial grade barium titanate powder was milled to $1 \mu \mathrm{m}$ particle size. To prepare the glass frit, the component oxides were powdered, mixed and then heated to $1000^{\circ} \mathrm{C}$ and quenched in distilled water. The glass frit was milled to about the same particle size as the barium titanate. The barium titanate and the glass powders were mixed together and added to the organic vehicle. In the adjustment of the viscosity of the paste, a Ferranti-Shirley cone and plate type viscometer was used. In the printing stage (shear rate $100 \mathrm{~s}^{-1}$ ), the value of viscosity was approximately $340 \mathrm{P}$ and at the levelling stage (shear rate $0,1 \mathrm{~s}^{-1}$ ), approximately $15000 \mathrm{P}$. 


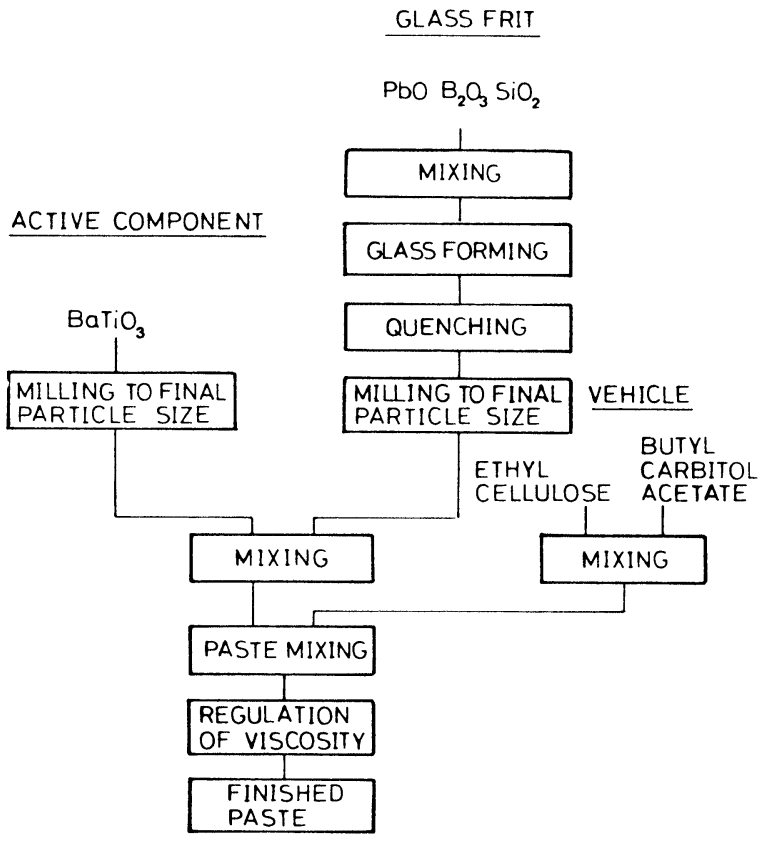

FIGURE 1 Preparation of the capacitor paste.

\subsection{Test Capacitors}

In test capacitors the dielectric layer was made to overlap the bottom electrode, and the top electrode determined the surface area of the capacitors; the areas used were 1, 2, 4, 6 and $9 \mathrm{~mm}^{2}{ }^{2}$ The capacitors

TABLE I

The materials and the firing temperatures of the test capacitors.

\section{Firing}

temperature $\left({ }^{\circ} \mathrm{C}\right) \quad$ Top electrode paste

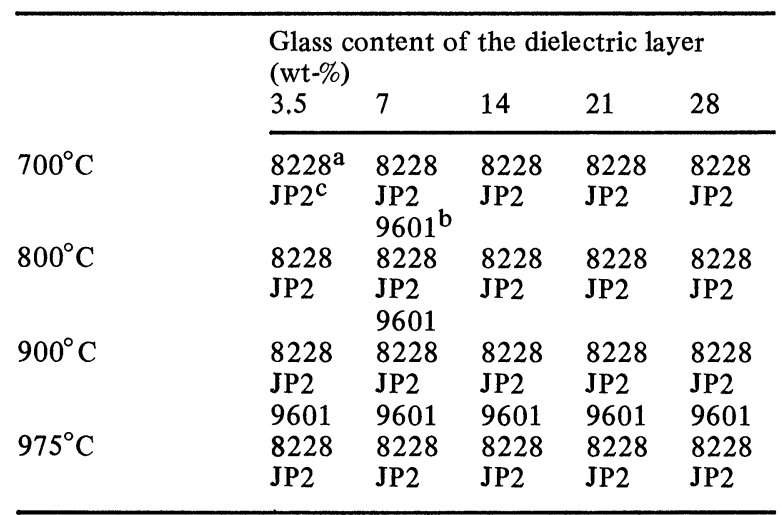

The bottom electrode paste was Du Pont 822 , fired at $975^{\circ} \mathrm{C}$.

\footnotetext{
${ }^{\mathrm{a}}$ Du Pont 8228

bESL 9601

cPrepared Pd/Ag-conductor paste
}

were printed on substrates (Kyocera $96 \% \mathrm{Al}_{2} \mathrm{O}_{3}$ ) using a 280 mesh screen for the conductor layers and a 60 mesh screen for the dielectric layer. The layers were fired separately, the bottom electrode always at $975^{\circ} \mathrm{C}$ but the dielectric layer and top electrode at various test firing temperatures, viz. 700, 800, 900 and $975^{\circ} \mathrm{C}$.

The bottom electrode paste of the test capacitors was in all cases Du Pont 8228 and the top electrode paste variously Du Pont 8228, ESL 9601 and JP2 prepared for this work. Du Pont 8228 is a $\mathrm{Pd} / \mathrm{Ag}$ conductor paste particularly intended for capacitors containing a bismuth trioxide additive. ESL 9601 is a fritless type $\mathrm{Pd} / \mathrm{Ag}$ conductor paste and JP2 contains $\mathrm{Pd} / \mathrm{Ag}$ and the same lead borosilicate glass as the dielectric pastes. The materials and the firing temperatures of the test capacitors are shown in Table I.

\section{MEASUREMENTS AND DISCUSSION}

The measurements for the uncapsulated test capacitors were made under normal laboratory conditions $\left(22^{\circ} \mathrm{C} \pm 2{ }^{\circ} \mathrm{C}, \mathrm{RH} 30 \%\right)$. Because of the ageing properties of dielectric materials, measurements were started not earlier than 10 days after the last firing cycle.

The capacitance and loss factor were measured at a frequency of $1 \mathrm{kHz}$ and a voltage of $1 \mathrm{~V}$ peak to peak by using a GR impedance bridge 1608-A. The dependence of the capacitance and of the loss factor on frequency was measured between $30 \mathrm{~Hz}$ and $50 \mathrm{kHz}$ with the impedance bridge mentioned above and up to $10 \mathrm{MHz}$ using a GR impedance bridge 1606-B. The temperature dependencies were measured between $-60^{\circ} \mathrm{C}$ and $+100^{\circ} \mathrm{C}$ using a Weiss environment test chamber type 160/80-180 DU. To eliminate the effects of humidity, the capacitors were encapsulated using a silicon epoxy cement. The breakdown voltage was determined by increasing the DC voltage over the dielectric until breakdown occurred. The voltage dependence measurements were made with a GR impedance bridge 1608 -A by adding 0 to $100 \mathrm{~V} \mathrm{DC}$ to the measuring $\mathrm{AC}$ voltage.

A Taylor-Hobson Talysurf and a Talystep surface profile meter were used to measure the thickness and roughness of the dielectric layer. The surface quality was also examined by using a scanning electron microscope.

\subsection{Capacitance Density}

The capacitance density of a thick film is dependent on many different factors, the separation of which is difficult. In addition to the firing temperature, the 


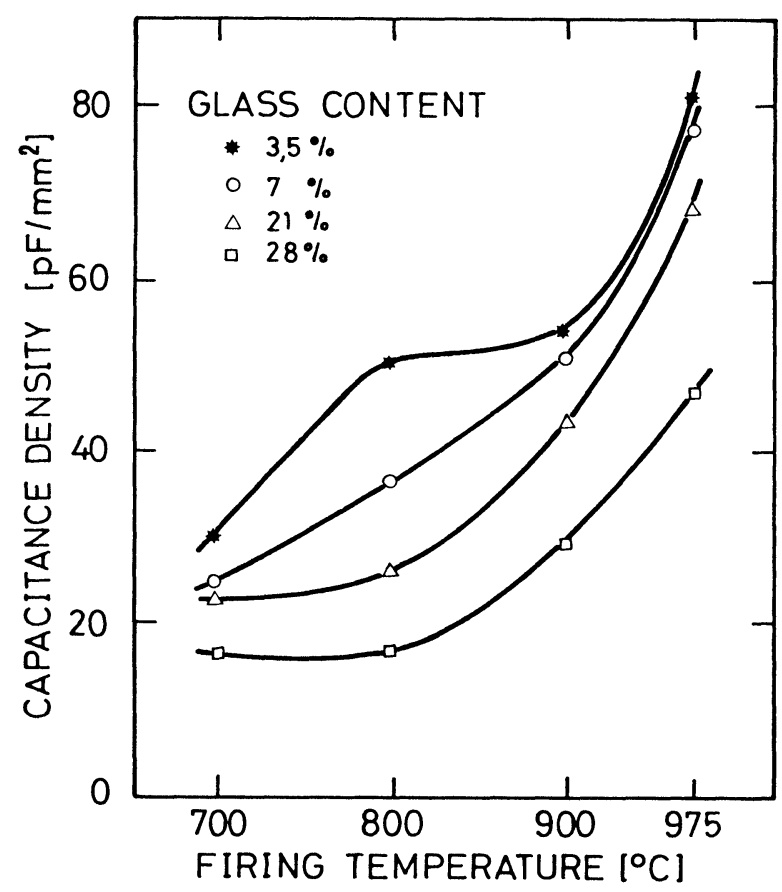

FIGURE 2 The capacitance density as a function of firing temperature for the glass frit contents of a dielectric of 3.5, 7,21 and $28 \mathrm{wt}-\%$. The top electrode material was Du Pont 8228 and the thickness of the dielectric layer was $50 \mu \mathrm{m}$.

glass frit content of the dielectric paste and the composition of the frit of the conductor paste are important factors.

There is a strong increase in the capacitance density between the firing temperatures of $700^{\circ} \mathrm{C}$ and $975^{\circ} \mathrm{C}$ (Figures 2, 3 and 4). This increase is partly due to the decrease in the number of pores: the thickness of the dielectric layer was found to reduce by 2 to $7 \%$ during firing. The increase in total capacitance was also caused by the flow of the glass component of the top electrode material into the pores on the surface of the dielectric layer. The rapid increase in capacitance density above a firing temperature of $900^{\circ} \mathrm{C}$ (Figure 2) in the case of the Du Pont 8228 conductor paste was caused by the bismuth trioxide content of the conductor paste which actively reacts at higher temperatures with the barium titanate and probably with the components of the glass. ${ }^{4}$ The crystalline phases formed in these reactions are often ferroelectric with a high dielectric constant. The effect of this kind of reaction was not found in the case of the JP2 paste which had no bismuth trioxide (Figure 3).

An attempt to determine the effect of the densification of the dielectric layer on the capacitance

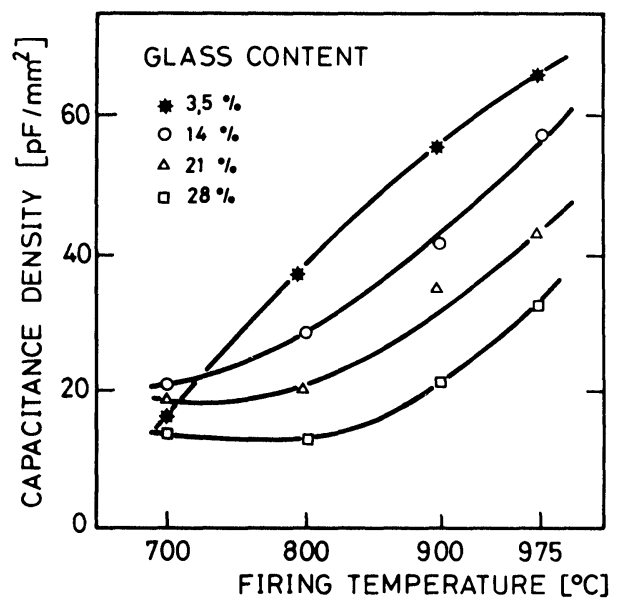

FIGURE 3 The capacitance density as a function of firing temperature for the glass content of a dielectric of $3.5,14$, 21 and $28 \mathrm{wt}-\%$. The top electrode material was JP2 and the thickness of the dielectric layer was $50 \mu \mathrm{m}$.

density was made by using a fritless conductor paste, ESL 9601 (Figure 4). This electrode, however, did not adhere firmly to the surface of the dielectric layer due to the pores of the transition region between the conductor and dielectric layer. At higher firing temperatures the fritless electrode paste adhered to the surface of the dielectric layer better and a higher capacitance density was achieved than with the frit conductor paste.

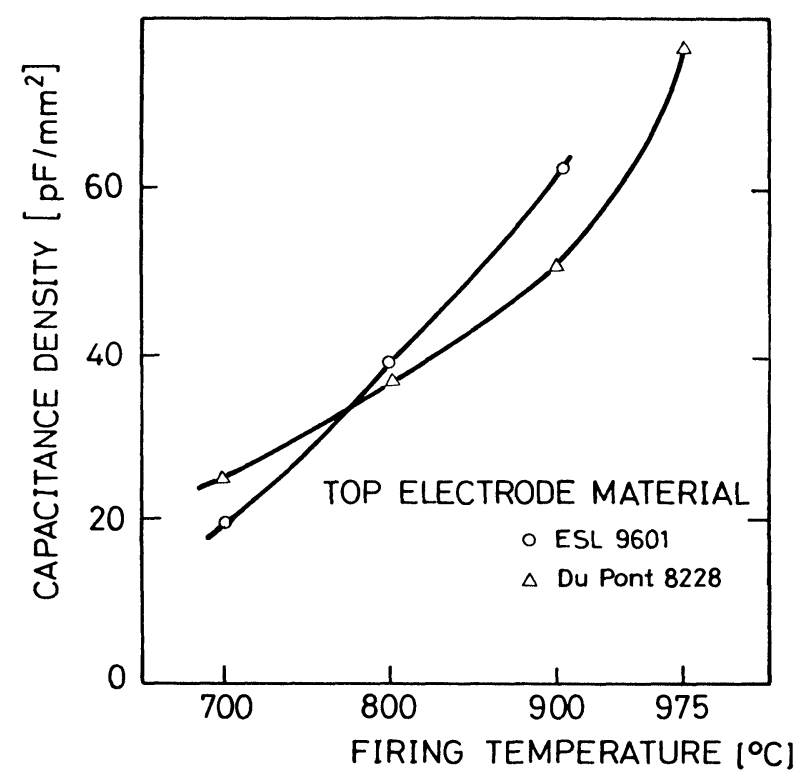

FIGURE 4 The capacitance density as a function of temperature when the glass content was $7 \mathrm{wt}-\%$ and the thickness of the dielectric layer was $50 \mu \mathrm{m}$. 


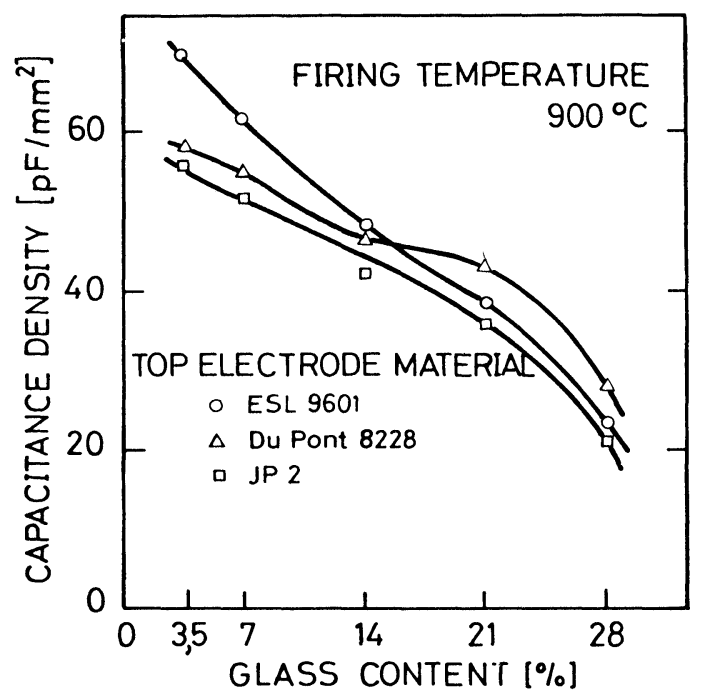

FIGURE 5 The capacitance density as a function of the glass content of the dielectric layer for the firing temperature $900^{\circ} \mathrm{C}$. The thickness of the dielectric layer was $50 \mu \mathrm{m}$.

Figure 2 shows also the effect of the glass content of the dielectric layer on the capacitance density. When the glass content increased from 3.5 to $28 \mathrm{wt}-\%$. the capacitance density was almost halved. Because the barium titanate particles of the transition region were already covered with glass during the firing of the dielectric paste, the difference between the capacitance densities decreased as the glass content in the dielectric layer increased. The scanning electron microscope figures showed that the barium titanate particles were totally covered by glass and that the pores had disappeared.

Figure 5 shows the effect of the top electrode material on the capacitance density. In dielectric layers of low glass content there was a noticeably larger capacitance density with the fritless conductor paste ESL 9601 than with the JP2 paste. Higher capacitance densities with higher glass contents were achieved by using the Du Pont 8228 conductor paste because of the reactions caused by bismuth trioxide with barium titanate.

\subsection{Loss Factor}

The dependence of the loss factor on the firing temperature presented in Figure 6 for two top electrode pastes, was not as great as the dependence of the capacitance density on the firing temperature. As the firing temperature rose from $700^{\circ} \mathrm{C}$ to $900^{\circ} \mathrm{C}$ the losses doubled, but after $900^{\circ} \mathrm{C}$ they began to saturate out or fall. The increase in losses was caused by the densification of the dielectric layer, while the saturation and falling of the losses was due to the increase in the series capacitance of the glass layer between the dielectric layer and the top electrode.

The glass content of the dielectric layer had a relatively small effect on the loss factor of the capacitor up to about $20 \mathrm{wt}-\%$ glass content (Figure 7).

\subsection{Breakdown Voltage}

The breakdown voltage decreased when the firing temperature increased as seen in Figure 8. The breakdown voltage also decreased when the glass content of the dielectric layer increased towards $20 \mathrm{wt}-\%$; thereafter, the breakdown voltage increased.

\subsection{Component Characteristics}

The measurements of the characteristics were made on capacitors which had a firing temperature of
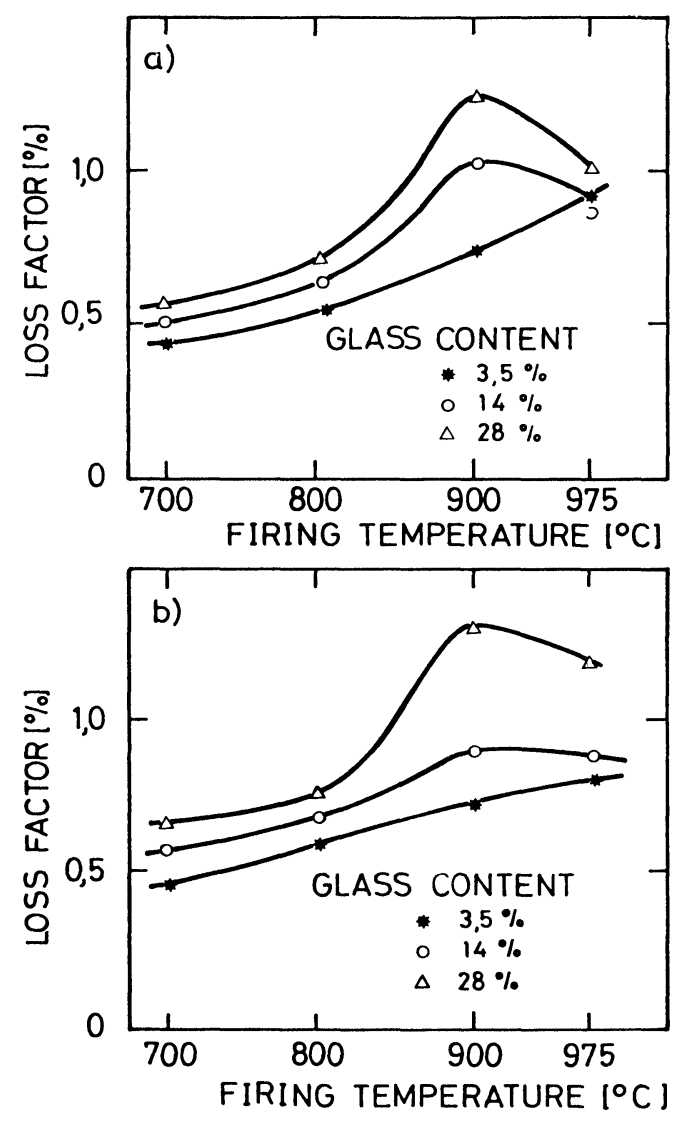

FIGURE 6 The loss factor as a function of temperature when the top electrode material was (a) Du Pont 8228 and (b) JP2. 


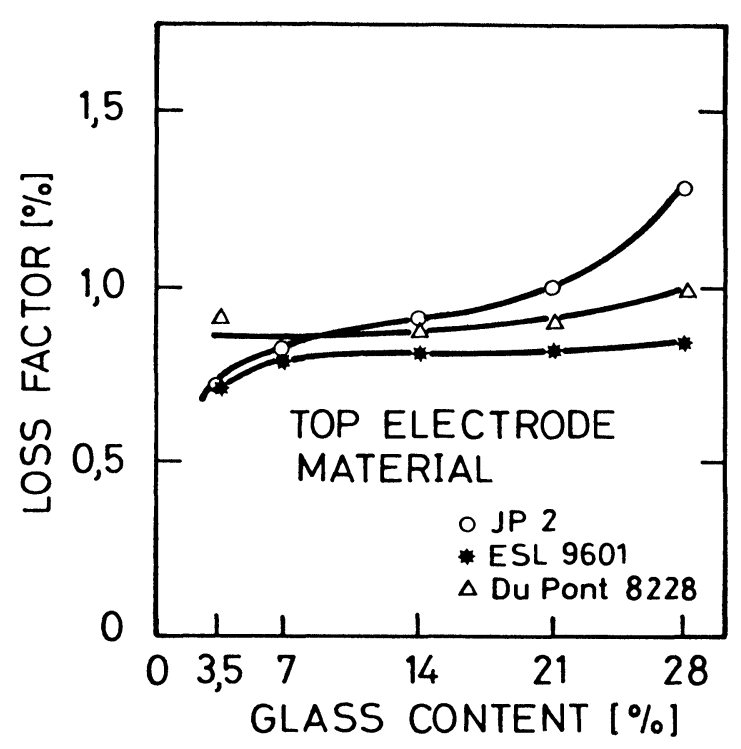

FIGURE 7 The loss factor as a function of the glass content for different top electrode materials when the firing temperature was $900^{\circ} \mathrm{C}$.

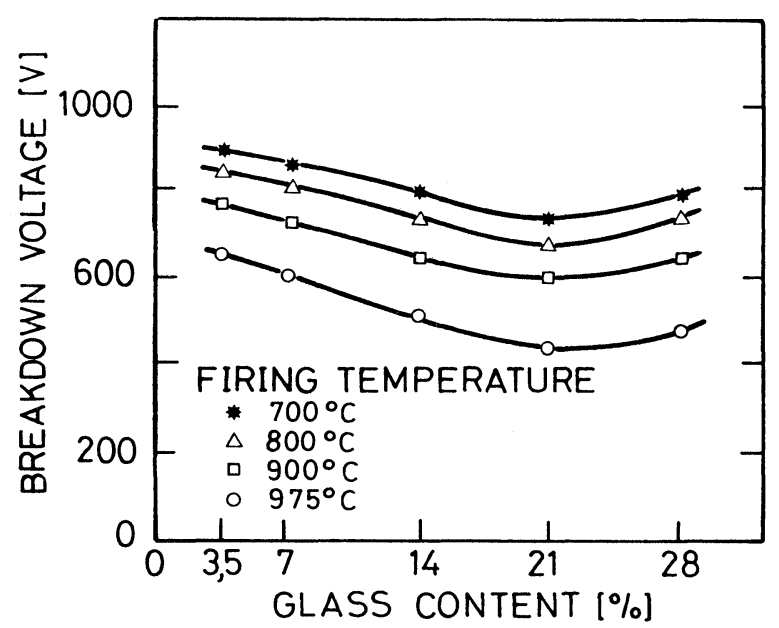

FIGURE 8 The breakdown voltage as a function of glass content when the top electrode material was Du Pont 8228 and the thickness of the dielectric layer was $50 \mu \mathrm{m}$.

$900^{\circ} \mathrm{C}$, a dielectric glass frit content of $7 \mathrm{wt}-\%$, and with a top electrode paste of Du Pont 8228. The capacitance density and losses as a function of temperature, voltage and frequency are shown in Figures 9 to 13 . Figure 14 shows the ageing of the capacitance at room temperature and shows ageing of about $3 \% /$ decade being normal for ceramic ferroelectric materials. ${ }^{5}$ Figure 15 shows the effect of the polarization current. The leakage current, not including polarization current, is very small, i.e. in the order of $\mathrm{pA} / \mathrm{mm} .^{2}$

\section{CONCLUSION}

The capacitance density of a thick film barium titanate capacitor is strongly dependent on the firing temperature. This dependence is caused not only by the densification of the dielectric layer, but also by the reduction in the effect of the series capacitance caused by the glass between the top electrode and the dielectric layer and by reactions between the barium titanate of the dielectric layer and bismuth trioxide. As the glass content of the dielectric layer increased,

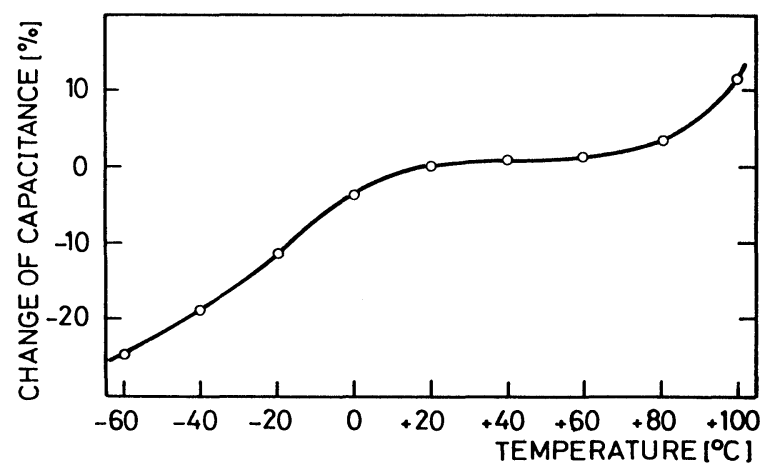

FIGURE 9 The change of capacitance as a function of temperature when the firing temperature was $900^{\circ} \mathrm{C}$.

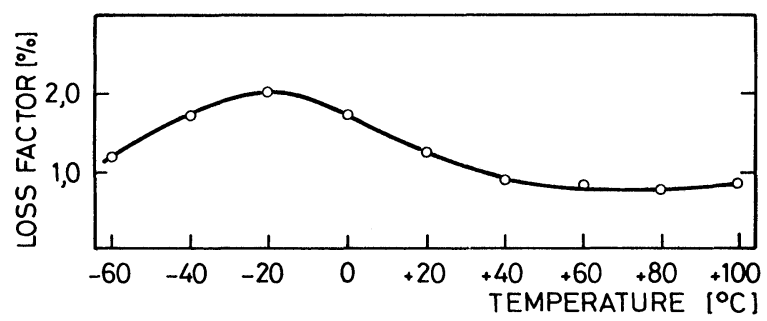

FIGURE 10 The loss factor of the capacitors as a function of temperature.

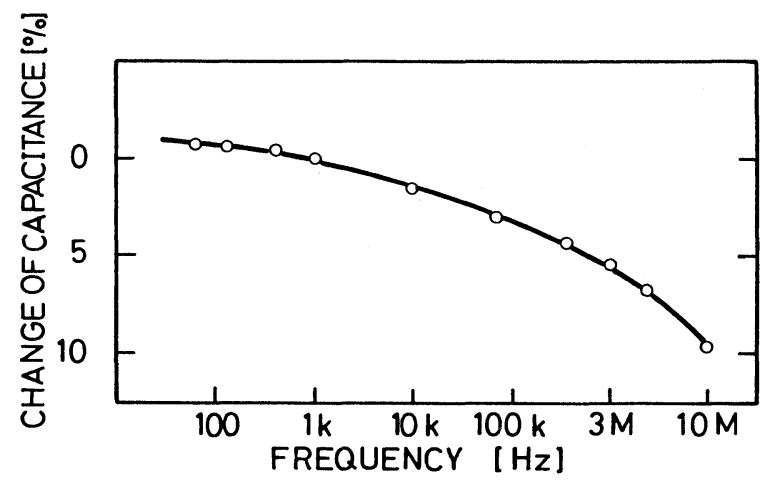

FIGURE 11 The change of capacitance as a function of frequency. 


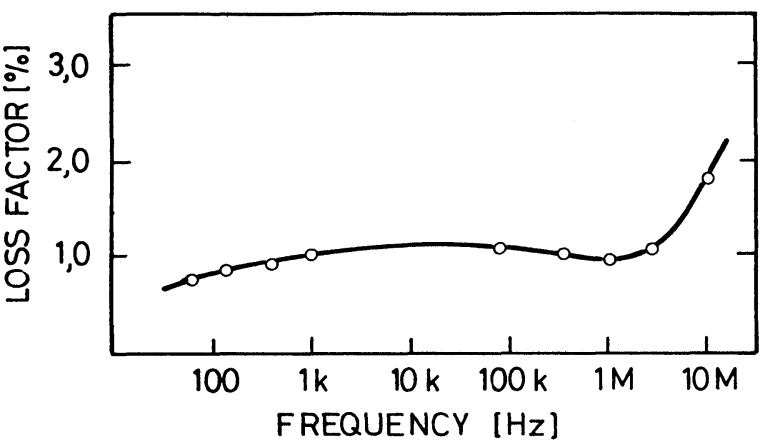

FIGURE 12 The loss factor as a function of frequency.

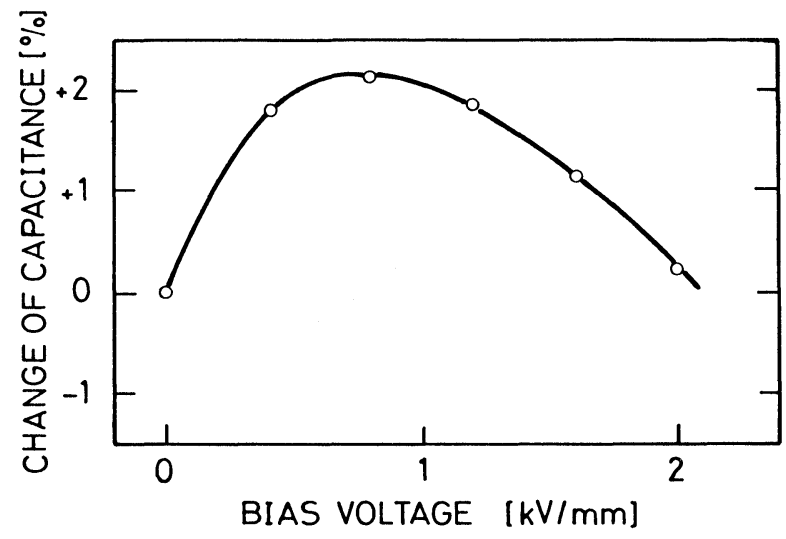

FIGURE 13 The change of capacitance as a function of bias voltage.

the capacitance density at first slowly decreased because the glass filled the pores of the dielectric, but the decrease was rapid when all the pores were full of glass contents of over $20 \mathrm{wt}-\%$.

The loss factor of the capacitor increased markedly up to the firing temperature of $900^{\circ} \mathrm{C}$, but after that levelled. This was due to the densification of the dielectric layer and the removing of the glass layer between the electrode and the dielectric.

The breakdown voltage of the capacitor decreased as the firing temperature and the glass content increased but it started to increase again at a glass content of $20 \mathrm{wt}-\%$.

The characteristics of the test capacitors with 7 wt-\% glass content were similar to those of the ceramic barium titanate but were reduced by the effect of the glass and the porosity.

The ability to prepare pastes under laboratory conditions makes it possible to study the effects of the components of the pastes. In addition, it allows one to develop special pastes. The knowledge

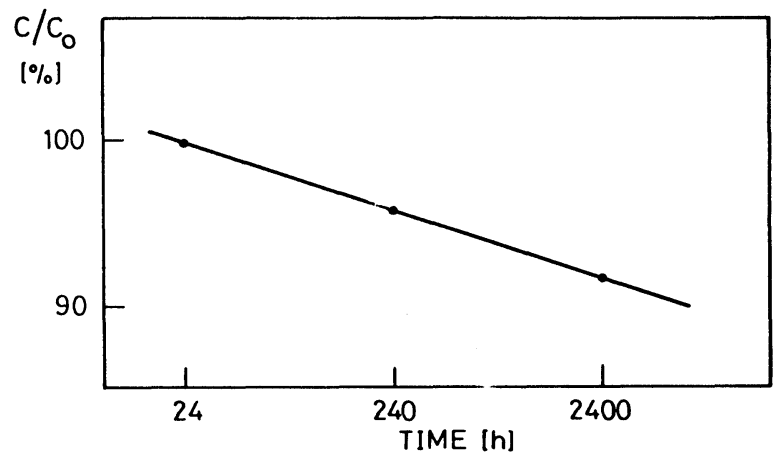

FIGURE 14 The room temperature, shelf ageing of the capacitance, when the firing temperature was $900^{\circ} \mathrm{C}$ and the glass content $7 \mathrm{wt}-\%$.

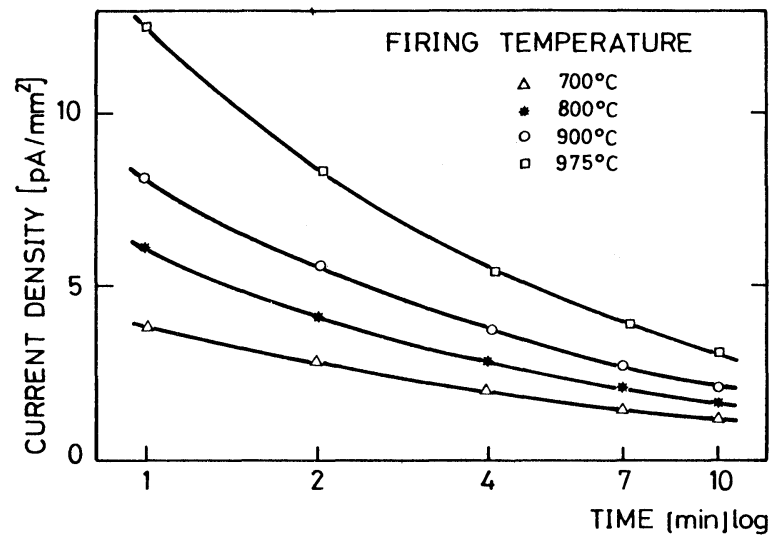

FIGURE 15 The leakage current density of the capacitors as a function of time when the capacitance have been fired at different temperatures.

obtained from the preparation of the pastes is also useful in rating commercial pastes.

\section{REFERENCES}

1. Ikegami, A., Arima, H. and Abe, K. Thick film capacitor materials of the powder-glass binary systems and their dielectric properties. Proc. European Hybrid Microelectronic Conf., 271 (1979).

2. Hamer, D.W. Ceramic Capacitors for Hybrid Integrated Circuits, ISHM Proceeding 99-109 (1968).

3. Kinoshita, K. and Yamaji, A. Grain size effects on dielectric properties in barium titanate ceramics, Journal of Applied Physics 47, 371 (1976).

4. Hoffman, L.C. and Nakayama, T. Screen printed Capacitor Dielectrics, Microelectronics and Reliability 7131 (1968).

5. Delaney, R.A. and Kaiser, H.D. Multiple-Curie-Point Capacitor Dielectrics, IBM Journal 11, 511-519 (1967). 

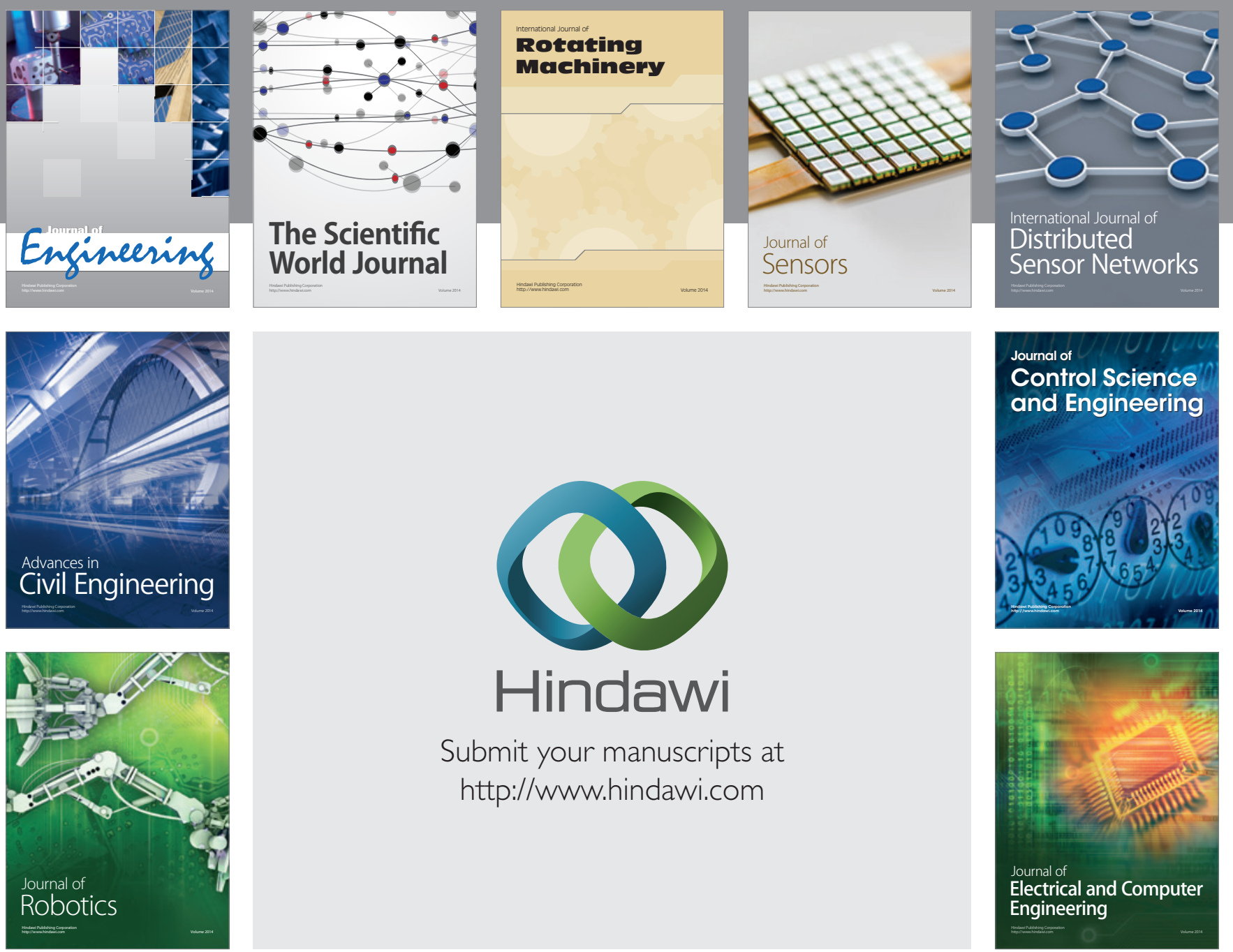

Submit your manuscripts at

http://www.hindawi.com
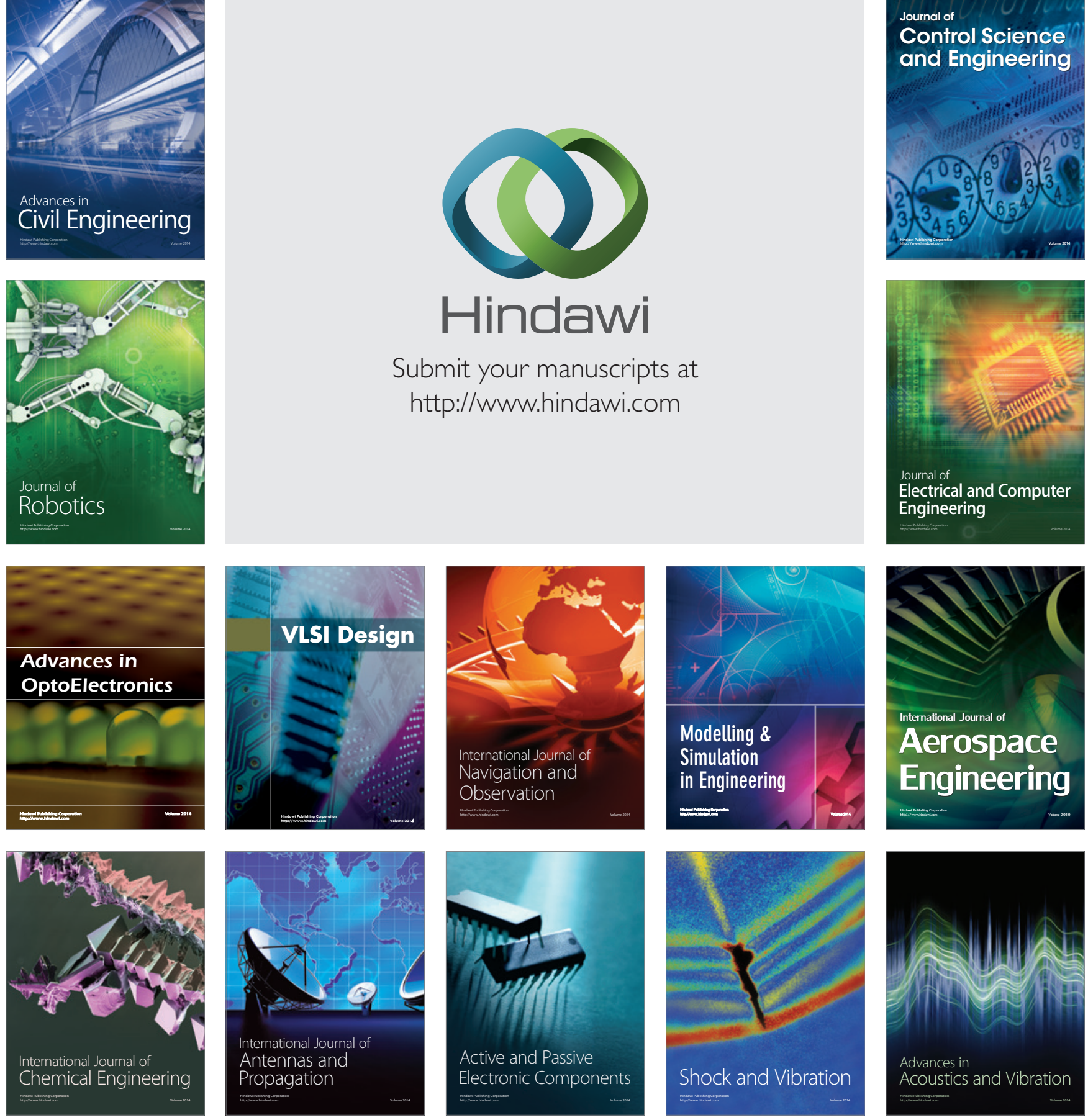